\title{
CrimRxiv •
}

\section{“Title IX isn't for you, it's}

for the university": Sexual

violence survivors'

experiences of

institutional betrayal in

Title IX investigations

Katherine Lorenz ${ }^{1}$, Rebecca Hayes ${ }^{2}$, Cathrine Jacobsen ${ }^{3}$

${ }^{1}$ California State University-Northrdige, ${ }^{2}$ Central Michigan University,

${ }^{3}$ California State University-Northridge

Published on: Nov 07, 2021

DOI: $10.21428 / c b 6 a b 371.1959 e 20 b$

License: Creative Commons Attribution 4.0 International License (CC-BY 4.0). 


\section{ABSTRACT}

Institutional betrayal occurs when an institution fails to appropriately respond to harm experienced by a member of the institution, such as through a failure to act or a mishandling of cases. The concept has been applied to the higher education institution (HEI) response students who experience sexual violence, particularly Title IX investigations, showing that institutional betrayal is common among student survivors. Yet, to our knowledge, institutional betrayal in HEI Title IX investigations has not been qualitatively explored. We conducted interviews of sexual violence survivors $(\mathrm{N}=21)$ who participated in a Title IX investigation at a U.S. HEI to understand their experiences of institutional betrayal. We found that all participants experienced some form of institutional betrayal during the Title IX investigation. Through grounded theory analysis, we identified themes of survivors' experiences of institutional betrayal including HEI self-protection from liability, lack of agency, HEI culture, and lack of proper support/resources. We discuss implications for institutional responses to survivors that minimize the risk of institutional betrayal.

\section{Introduction}

Sexual violence (including harassment and assault) in higher education is a common experience. Approximately a quarter of undergraduate students experience sexual violence, with figures at some institutions reaching as high as 48\% (AAU, 2019; Bloom et al., 2021; Edwards et al., 2019; Holland \& Cortina, 2017; Zinzow \& Thomsom, 2011; Smith \& Freyd, 2014) and graduate students/workers experiencing rates over 50\% (Rosenthal et al., 2016; Bloom et al., 2021). Despite the commonality of sexual violence, most who experience violence are unlikely to report it to campus authorities (e.g., campus law enforcement, professors, employees), with figures ranging from 428\% (Cantor et al., 2015; Ahrens et al., 2007; Fisher et al., 2003) with 25\% of female students telling no one at all (Walsh et al., 2010). While there are a variety of reasons for not reporting violence to campus authorities, it is common for students to not report because they think that nothing will be done (Lindquist et al., 2016) despite HEIs Title IX obligations to appropriately respond to sexual violence experienced by students.

Title IX of the Education Amendments of 1972 (Title IX) prohibits sex discrimination in higher education to ensure that students have equal access to educational opportunities at their HEI. One of the requirements is that higher education institutions (HEIs) take prompt and effective action in response to reports of sexual 
violence (misconduct) that prevent students from participating in education. This legislation requires that HEIs receiving federal funding have a Title IX office (though not always operating under this title) charged with creating a formal mechanism for receiving student reports of misconduct and to appropriately investigate them (U.S. Dept. of Education, 2020). The demand for compliance with this policy was emphasized in President Obama's 2011 Dear Colleague Letter accompanied by guidelines for Title IX practice. In 2020, now former Secretary of Education Betsy DeVos enacted wide-scale revisions to the Obama-era guidelines, rolling back many of the protections offered to survivors in the name of due process for those accused (Grayer \& Stracqualursi, 2020). While the Biden administration deliberates over the DeVos reform, survivors are subjected to a process that is not centered around their needs (Georgetown Voice Editoral Board, 2021; Grayer \& Stracqualursi, 2020).

While formal mechanisms for reporting and responding to sexual violence are a requirement of HEIs receiving federal funding, the budding scholarship suggests that these processes are more harmful than helpful to survivors (Georgetown Voice Editorial Board, 2021; Graham et al., 2019; Hayes et al., under review; Know Your IX, 2021; Lorenz et al., under review). Research suggests that Title IX investigations are damaging to those who report and fails to protect student survivors through a lack of action by the HEI, termed institutional betrayal (Know Your IX, 2021; Smith \& Freyd, 2013). Institutional betrayal in Title IX investigations is a relatively new concept and area of exploration, but the mounting evidence of HEIs failure to respond and/or mishandling of cases via Office of Civil Rights complaints of Title IX violations (see OCR, 2021) shows that additional research is warranted to further develop this concept through the experiences of student survivors. We use a U.S. sample of undergraduate and graduate student/worker survivors to qualitatively explore their experiences with Title IX offices and the (in)actions of the HEI to further theorize the concept of institutional betrayal.

\section{Institutional Betrayal}

Institutional betrayal is a concept tied to Betrayal Trauma Theory, which draws a connection between increased posttraumatic symptoms among survivors of interpersonal abuse with the compounded trauma of betrayal by the institution (Freyd, 1994, 1996, 2008; Freyd et al., 2007; Smith \& Freyd, 2013, 2014). Betrayal Trauma becomes possible when a victim of interpersonal abuse is unable to detach from their abuser due to dependency for survivor and consequently enters a necessary state of betrayal blindness (i.e., overlooking signs of betrayal) (Freyd, 2013, 2014; Freyd \& 
Birrell, 2013, Freyd et al., 2001). As applied to HEIs, institutional betrayal can occur when a student is dependent on the institution for things that may be tied to their survival and/or upward mobility, such as education (e.g., college degree, career preparedness, networking) or financial (e.g., graduate worker income, scholarship, financial aid) or preventing sexual violence from continuing. The lack of validation of interpersonal trauma by the institution can predict the development of complex posttraumatic responses (Courtois \& Ford, 2009; Smith \& Freyd, 2013). Further, a lack of sustained awareness of harmful institutional practices at an individual level is a response to institutional betrayal that allows for maintenance of the institutional relationship (Smith \& Freyd, 2014). As an example, "pass the harasser" policies may acknowledge abuse but do nothing to address the underlying causes. The scholarship on institutional betrayal illustrates a pattern of inaction in response to sexual violence across institutions, and the necessity of continuing to document these patterns in research particularly among offices within these institutions that are specifically tasked with responding to sexual violence such as Title IX.

Institutional Betrayal occurs when the institution (in this case the HEI including Title IX) or agents of the institution (such as Title IX coordinators/investigators, but also faculty), fail to acknowledge or respond to interpersonal trauma/harmed experienced, or fail to act on behalf of the survivor's interests in response to the harm they experienced and disclosed within the context of the institution (Smith \& Freyd, 2013). This betrayal or inaction by the institution can include behaviors or responses of individuals and/or the institution, but also the policies and procedures in place (such as the HEI's Title IX guidelines or student conduct policies). This prevents the institution or agents of the institution from acting to meet the needs of the survivor or from preventing the harm from occurring in the first place. The relationship experienced between a HEI and students resembles that of interpersonal relationships in terms of its members trusting the institutional environment to be safe (Platt et al., 2009; Smith \& Freyd, 2014) and depend on the institution for their safety (Smith \& Freyd, 2013, 2014). When the institution fails to protect its members and to acknowledge interpersonal trauma, institutional betrayal occurs (Courtois \& Ford, 2009; Know Your IX, 2021; Smith \& Freyd, 2013, 2014). Indeed, Smith and Freyd's (2013) research found that $46 \%$ of female college students who had experienced unwanted sexual contact also reported at least one type of institutional betrayal.

There are a variety of ways in which institutional betrayal may occur with the trauma of sexual violence, with some examples including institutional failure to prevent these experiences from happening in the first place. Examples include: allowing individuals 
with prior allegations of sexual violence into the institution, creating an environment that allows the abuse to occur, and making it difficult to report violence (e.g., retaliation for reporting, inaccessible reporting procedures) (Smith \& Freyd, 2013). Institutional betrayal may also occur as an omission of protective, preventative, or responsive institutional actions (Smith \& Freyd, 2014). Institutional betrayal also occurs when the institutional environment allows for individuals of marginalized identities (e.g. LGBTQIA+ Black, Indigenous, People of Color (BIPOC), person with disabilities, etc.) to be treated differently, or when there are structural barriers within the institution that make it difficult for them to seek support (Smidt et al., 2019). It is common for Title IX investigators to be undertrained and burdened with competing responsibilities which can contribute to inactions such as those outlined above, but this is also indicative of structural issues in how sexual misconduct complaints are handled by the HEI (Wiersma-Mosley \& DiLoreto, 2018).

Research concerning Title IX student experiences imply that Title IX is not practiced in ways that protect student survivors, but are instead actively harmful to their wellbeing (Hayes et al., under review; Know Your IX, 2021; Lorenz et al., under review; Smith \& Freyd, 2013; Stader \& Williams-Cunningham, 2017; Smidt et al., 2019). Rather the Title IX procedures are used as a means of protecting the institution itself and its liability (Cruz, 2021). Institutional self-protection is a well-documented phenomenon in institutional betrayal literature and has been labeled one of several predictors of institutional betrayal (Smith \& Freyd, 2013, 2014; Stader \& WilliamsCunningham, 2017). Institutions of prestige have been linked to the covering-up of abuse and institutional betrayal (Stader \& Williams-Cunningham, 2017), which suggests prioritizing the institution's reputation over its obligation to protect the safety and trust of institutional members (Smith \& Freyd, 2014). Moreover, institutional failure to respond to sexual assault survivors' safety concerns effectively is noted in the literature as a negative and punitive repercussion for reporting, which may cause a silencing effect and deter future survivors from reporting as well (Smith \& Freyd, 2013, 2014; Stader \& Williams-Cunningham, 2017). Consequently, institutional betrayal occurs when HEIs prioritize the institution over ensuring a safe environment for students and support once harm does occur.

\section{Effects of Institutional Betrayal}

Student survivors file with their Title IX office expecting protection and support but are likely to be met by failing procedures and experience institutional betrayal trauma using this route (Smith \& Freyd, 2013, 2014). The powerful position of an institution 
enables it to either imply support and healing or worsen the impacts of trauma experienced by student survivors (Smith \& Freyd, 2014). When abuse occurs in an institutional setting, the adverse effects are exacerbated when co-occurring with institutional betrayal (Smith \& Freyd, 2013, 2014; Stader \& Williams-Cunningham, 2017). Consequently, students have regarded the Title IX reporting process as worse than the original violence they experienced (Cruz, 2021; Hayes et al., under review; KnowYourIX.org, 2021).

The institutional failure to acknowledge interpersonal trauma directly causes the increase in posttraumatic symptoms (Courtois \& Ford, 2009; Smith \& Freyd, 2014). Institutional betrayal is associated with an increase in post-traumatic symptoms such as lack of memory about the abuse, physical health consequences, delays in reporting and help seeking, increased anxiety, depression, sexual dysfunction, and dissociation and disengagement from formerly valued institutions (Freyd, 1996; Platt et al., 2009; Smith \& Freyd, 2013, 2014; Sadler et al., 2004). LGB students are more likely than heterosexual students to experience institutional betrayal and subsequent negative psychological and physical health outcomes (Smidt et al., 2019; Smith et al., 2016). The concept of institutional betrayal and its adverse impact has been established in the literature but needs to be explored further in the context of Title IX investigations.

\section{Current Study}

With the relatively recent scholarly focus on HEI responses to sexual violence via Title IX, we need to conduct research exploring survivors' experiences to build (not necessarily reform) mechanisms that are supportive and healing rather than harmful. The institutional betrayal research illustrates that these processes often leave survivors feeling betrayed by the institution, but further research - particularly qualitative research - is essential to continuing to understand institutional betrayal based on survivors' experiences and informing decisions about how institutions should respond to survivors. We continue to build scholarship with this study that explores the Title IX experiences of survivors who participate in U.S. Title IX investigations. We include a sample of both undergraduate and graduate students to disaggregate the different experiences with the Title IX process given the different functions of these groups within the university. We use a grounded theory approach to explore survivors' experiences with Title IX (Corbin \& Strauss, 2008, 2015; Glaser \& Strauss, 1967) and the theme of institutional betrayal naturally emerged from our data which is the focus of the present study. 


\section{Methods}

\section{Recruitment Procedures}

We use qualitative interview data from a sample of 21 participants $\underline{1}$ to explore undergraduate student and graduate student/worker experiences with the Title IX process . We recruited participants through social media advertisements (Twitter, Facebook, Instagram), through professional email listservs (e.g., faculty department listservs, university gender and women's studies listservs, and American Society of Criminology's Division on Women and Crime and Division on Queer Criminology), and snowball sampling. Snowball sampling is a common means for accessing hard to reach populations, such as sexual violence survivors (Atkinson \& Flint, 2001). The research team posted social media advertisements to their personal pages with the request that those viewing share the post. The advertisements included information about the study and invited anyone who had contact with a U.S. Title IX office as a result of sexual misconduct to provide their contact information (via an anonymous Qualtrics survey) to be contacted for an interview via email. Invitations to participate were extended to adult men, women, transgender, and non-binary individuals who had contact with a Title IX office while enrolled at a HEI in the United States of America as an undergraduate student, graduate student/worker, or both. There were no other eligibility or exclusion criteria for the study. Because participants may have known the interviewers given our recruitment strategy and professional affiliations, we provided our names and affiliations to give participants the opportunity to select either of the principal investigators as their interviewer. We recruited participants and conducted interviews from July 2020 through June 2021. There were no financial incentives to participate in this study. All procedures were approved by the California State University-Northridge Institutional Review Board (IRB).

\section{Interview Procedures}

Once the interview was scheduled, we provided participants with an electronic consent form (via Qualtrics) for participants to review and accept prior to the interview. At the start of each interview, we asked participants to verbally confirm that they had reviewed and agreed to the consent information. All interviews were conducted over Zoom, and lasted from 1-2 hours each. Participants were given the option to hold the interview over audio or audio/video conferencing, based on their level of comfortability. Both interviewers (study PIs) employed a feminist methodological approach to interacting with participants which includes practices such as building rapport, providing support service referrals, allowing participants to exercise choice 
and control during the interview, and providing supportive responses to content during the interview (Dickson-Swift et al., 2007). We conducted the interviews using a semistructured protocol spanning topics related to the participants' experiences with the Title IX office and investigation process, their feelings, and recommendations for Title IX practices and procedures. During the interview, the interviewers would regularly take analytical notes and ideas based on the interview content which continued into the analysis process (i.e., memoing; Creswell \& Poth, 2018). Following the completion of interviews, the audio file was securely transferred to a third-party transcriptionist for transcription. The PIs reviewed the transcript for accuracy. Data analysis was conducted with de-identified interview transcripts and names were either chosen by the participant or assigned during coding of the transcripts using randomly selected Goddess names.

\section{Measures}

The interview protocol focused on both the institutional and individual experience. For the present study we are looking at individual feelings about the institutional response/process to understand survivors' experiences with Title IX. During grounded theory analysis (described below), institutional betrayal naturally emerged from the data and therefore is the focus of the present study. We approach the conceptualization/measurement of institutional betrayal from Smith and Freyd's (2013, 2014) work on betrayal trauma and institutional betrayal. While we considered Smith and Freyd's $(2013,2014)$ quantitative measure of institutional betrayal which includes items such as: 1) not taking proactive steps to prevent this type of experience; 2) creating an environment in which this experience seemed common or no big deal; 3 ) creating an environment in which the experience seemed more likely to occur; 4) making it difficult to report the experience; 5) responding inadequately to the experience; 6) covering up the experience; and 7) retaliation for this experience, to inform our analysis process (detailed below). We use a grounded theory approach to extend our understanding and conceptualization of institutional betrayal based on themes that naturally emerged from our data. For example, the pillar of institutional betrayal identified by Smith \& Freyd $(2013,2014)$ that quantitatively asks if a person indicated that the institution inadequately responded to the experience, we qualitatively explore how the institution responded.

\section{Data Analysis}

This exploratory qualitative study uses an inductive, grounded theory approach to analysis (Glaser \& Straus, 1967; Creswell \& Poth, 2018; Corbin \& Strauss, 2008; 
Corbin \& Strauss, 2015; Charmaz, 2006; Strauss \& Corbin, 1990) to form a theoretical model to enhance our understanding and conceptualization of institutional betrayal by HEIs. Once interviews were transcribed, the interviewers read the transcripts to check for accuracy. We imported the transcripts into MaxQDA 2018 qualitative analysis software for transcription. The codebook for data analysis was developed based on first-impression codes observed during the interviews and several iterations of sample coding by the interviewers resulting in revisions of adding, removing, and combining codes. The codebook was finalized once both interviewers could code a sample of interviews using the existing codebook. The final codebook consisted of 38 codes under 6 headings/families.

The two PIs/interviewers collected and analyzed data simultaneously which involved memoing during interviews (i.e., taking notes on ideas related to the content raised during by participants, including institutional betrayal) and the coding process (Creswell \& Poth, 2018). We then analyzed the interviews using open coding which involved reading the transcripts and coding for the major categories of information (Corbin \& Strauss, 2008) using MaxQDA 2018 qualitative analysis software. We used broad codes for the initial round of open coding, for example, we coded using the term "institutional betrayal" for anything that could be considered institutional betrayal based on the literature. After coding each interview, we met to discuss the application of codes and determine any inconsistency in the use of codes, which was then discussed to reach a consensus between the two coders (Lorenz et al., 2018). Following the initial round of open coding, we used axial coding to further detail thematic categories or sub-codes to further explain the core phenomenon, which in this case was institutional betrayal (Corbin \& Strauss, 2015; Strauss \& Corbin, 1990). We again used an open coding method (Corbin \& Strauss, 2008) whereby we created sub-codes to represent the specific instance of institutional betrayal (e.g., issues with time, unjust process/outcome) without using a codebook. The two coders met to discuss the application and terminology of sub-codes and revised the coding based on this discussion to reach a full consensus that best represented what was occurring in the transcript.

After having written the findings for the study, we sent the results section to the interview participants to check that their experiences were accurately presented and quotations appropriately contextualized. We offered the participants the opportunity to directly edit the text or provide suggestions for how they would like to see the text revised (Kelly, 1991) and then sent the revised results back to the participants who requested changes to confirm their agreement with the changes. 


\section{Results}

\section{Sample Description}

Our sample consisted of $\mathrm{N}=21$ sexual violence survivors who reported to the Title IX office at their U.S. HEI. Our sample primarily consisted of cisgender women $(N=21$; $100 \%)$. We asked each participant about their racial/ethnic identification, with most participants identifying as white $(n=15 ; 71 \%)$, one Hispanic $(n=1 ; 4.5 \%)$, and one Black/African American $(n=1 ; 4.5 \%)$ and one South Asian $(n=1 ; 4.5 \%)$. We also had three participants who identified as multiracial ( $n=3 ; 13.5 \%)$, two of whom were Asian and white $(n=2)$ and one who identified as white and with Jewish ethnoreligion. Ages at the time of the interview ranged from 21 to 39 years $(M=28)$.

Most of our sample consisted of graduate students/workers at the time of their contact with their HEI Title IX office $(n=15 ; 71 \%)$, fourteen of whom were enrolled in doctoral/PhD programs or medical school. The remaining sample $(n=7 ; 33 \%)$ were enrolled in an undergraduate program at their time of contact with the Title IX office. One participant had contact with a Title IX office as both an undergraduate and graduate student regarding two different sexual violence experiences at two different institutions. We did not inquire during interviews about the circumstances of their sexual violence experience, but participants shared with us their relationship to the person who perpetrated the harm as it related to their Title IX experience: most participants shared that they were harmed by a professor in their department $(n=13)$, nine participants $(n=9)$ were harmed by a fellow student. Sixteen participants selfinitiated their report either to the Title IX office directly or to a mandated reporter, either intentionally or unintentionally. Overall, the pathway to contact with the Title IX office for fourteen participants was through a mandated reporter. Nine participants reported as a group with other students who had experienced harm by a single person.

\section{Qualitative Findings}

Through grounded theory analysis, we found that all participants $(n=21)$ experienced at least one form of institutional betrayal, which occurs when the Title IX office failed to acknowledge, adequately respond to, or act on behalf of the survivors' interests (defined above; Smith \& Freyd, 2013). Regarding general experiences of institutional betrayal, here is a representation of participants' experiences:

“[The university] just isn't here to care...I was failed by the university and most folks will just be silent because they [Title IX] operate as an institution to silence 
survivors...What [Title IX] taught me was that they will do anything to not give a damn about survivors. And that was reiterated." - Bia

“It [Title IX] doesn't care about protecting people from violence. It is violence." Anaisa

While the quotes above represent the general feelings of betrayal shared by these survivors, we identified eleven underlying themes of institutional betrayal that emerged from the data including: 1) HEI environment/culture; 2) Title IX office incompetence; 3) Unjust process/outcome; 4) Length of investigation; 5) Lack of proper support/resources; 6) Lack of protection; 7) Lack of agency; 8) Emotional labor; 9) HEI self-protection from liability; 10) Retaliation; 11) Responding to cases differently. These themes represent the ways participants experienced institutional betrayal and yet are not mutually exclusive, given that it was common for participants to experience multiple forms of betrayal $(n=20)$.

\section{HEI environment/culture}

We observed the first occurrences of institutional betrayal to be reflective of the culture and environment created by the institution $(n=16)$. The culture created barriers to survivors participating in their education without experiencing harm and/or to receive institutional support following the harm that occurred. In Tyche and Irene's experiences they were unable to get a response from the Title IX office to commence an investigation until they hired attorneys. Keres never received a response from the emails she sent to Title IX about requesting a safety accommodation, to which she commented "she [Title IX investigator] was trying to sweep it under the rug." For others, they logistically struggled to access the Title IX office and others found other difficulties to reporting. For example, participants like Anaisa and Brigid could not contact the Title IX office because they worked during the day. Circe commented on the geographic location of the Title IX office which was inaccessible to anyone without a vehicle.

These issues of access speak to the culture of the campus and their ability to consider student's needs in receiving these services. Whereas Ivy was trying to file a formal complaint and was met with resistance by the Title IX office, which she felt was "in fact trying to deter me [from filing a report]." In Clemencia's case, she explained "I was constantly treated by my department and the university that I had done a bad thing by reporting, being treated like a troublemaker." Nicole discussed the culture specifically in the STEM field where students are afraid to report to Title IX due to the 
harmful treatment they receive which she described as "abusive", "disappointing" and "the worst". In consequence to the betrayal that occurred due to the HEI culture/environment, Maybelline as a graduate worker felt unwelcome and like an outsider in academia throughout the Title IX process, ultimately causing her to leave the academia and pursue another career. Joanna commented that "[my report] not being taken seriously made me feel like the program, the university, wasn't a good, safe place, or stable place, for me to do my work." For Rachel, she stated that she "lost complete faith in the school" due to the "demoralizing" treatment she received during the Title IX investigation.

\section{Title IX incompetence}

Participants used terms like "incompetence" when describing their experience with the Title IX office, and/or commented on continuous mistakes made by the office regarding their case $(n=15)$. As Irene explained, she found the office to be "disorganized...understaffed and overworked" which made her feel like her experience was not important to them. Similarly, Ivy described the Title IX investigation as "a hot mess from start to finish...I just had a complete lack of confidence in their execution of anything. It seemed like they were never prepared. Like they were always reactive and not preventative." When Keres' no-contact order and communications with the Title IX office were riddled with errors (such as the no-contact order listing her abuser as a professor, who was indeed a student, and she was the instructor) she commented that these errors "were just the beginning...I just felt like nobody [in the Title IX office] knew what to do."

The incompetence experienced by participants also extended to the Title IX office's ability to recognize power dynamics involved in sexual harm. Anaisa, Harmonia, Clemencia, Tyche, and Tawny explained they struggled to get the investigators to understand the power imbalance between professors and graduate workers that enabled the abuse to occur. Tawny and the others she reported with noted that the Title IX investigators ignored the connections between a series of survivors' reports, ignoring that sexually based harm frequently occurs in patterns. As Andarta stated: "it was clear they [Title IX] had very little training on trauma-informed approaches." For participants like Maybelline and Rachel, the incompetence of the office was so frequent that it led her to question whether it was intentional as a way to exhaust survivors into dropping the complaint. Maybelline questioned: "Is it incompetence or is it evil?" 


\section{Unjust process/outcome}

Frequently, participants were met with what we refer to as an unjust process or outcome where their complaints were ignored, dismissed, or met with inaction by the institution $(\mathrm{n}=16)$. For participants like Bia, Tawny, Joanna, and Maybelline, their case was not even investigated and they were given no explanation.

"My expectations were that they would go through some type of investigation and that didn't happen at all and they kind of left me to navigate college and my experience like by myself basically." - Bia

"I kind of thought like okay they dropped my case because they were focusing on this really, you know, heinous one. But now I don't think that's true." - Maybelline

Maybelline reported in a group of other graduate workers who had experienced harm by a professor. Because she was never given a reason why her case was not investigated, she assumed Title IX was focusing their resources on the most egregious harm experienced in the group but later came to regard this as simple inaction by the HEI.

The inaction or unjust response by the institution can also refer to the outcome of the case. Seven participants were not informed when a decision about the investigation was made and/or were unable to access the actual sanctions imposed. Participants like Ivy and Harmonia were told they are unable to know the sanctions imposed against the person who harmed them because it was a faculty member, which fell under the purview of personnel. In cases where Title IX office investigated the case and found the perpetrator responsible for the harm, there was rarely any consequences for this person. Circe waited five weeks for sanctions to be imposed for a student who harmed her and was following her around campus. She later found that the student was suspended for the three remaining weeks of the semester and Circe would be on campus with him for the remaining two years of her undergraduate degree. Eos, Ivy, and Harmonia expressed concern and frustration that the faculty members who were found responsible in the Title IX investigation were still able to access students without supervision through teaching, mentorship, and hiring students in the research lab, which allows harm to potentially continue. Aletha was disappointed that the perpetrator was never held accountable when she expected support from the HEI, but particularly so because she endured the burden of the Title IX investigation for nothing in return. 
"I think my expectations about the whole [Title IX] process were a little bit too high. It made me feel like the university was going to hold him accountable, which ever ended up happening. It felt like nothing happened in the end. It felt like a very long process that required a lot of stress and work on my part and not so much on his [perpetrator]" - Alethea

We observed this in Clemencia's case also, where after being found responsible for misconduct spanning 10 years, the professor who harmed her (and six other students who reported) was simply able to retire. The professor who harmed Ivy was still able to hire graduate workers with the stipulation that he did not text them or have them to his house; Ivy was concerned that the lack of sanctions would enable this professor to continue perpetrating abuse against graduate workers. As Harmonia pointed out, the lack of accountability for faculty who perpetrate harm sends the message "well, don't fuck up again, but if you do, hide it better. Or use better fear tactics so people don't come forward or report you."

Indeed, in some cases perpetrators were found responsible and not met with any consequence, and actually were seemingly rewarded. For Alethea, the person who harmed her was found responsible and subsequently unable to interact with other graduate students. To accommodate this sanction, he was given a private office on campus, which Alethea interpreted as a benefit to him. Brigid commented that the professor who harmed her was put on a permanent (paid) sabbatical. This professor was still able to sublet their subsidized campus housing to graduate students, which was one of the abuses of power that Brigid experienced and reported.

\section{Length of investigation}

The Title IX guidelines from the 2011 Dear Colleague letter recommended that investigations have "prompt" resolution of 60 days from the report filed (U.S. Dept, of Education, 2020). Most of the participants' investigations took place under these regulations, with 14 participants noting issues with exceeding this timeline and frequently related problems like a lack of transparency regarding deadlines. Like Nicole stated; "There was never any timeline so never any deadline." It was common for participants to feel betrayed by drawn out investigations because they felt like their experience was not taken seriously and not prioritized.

"It was absolutely not transparent, which was the thing we struggled with most because at every step we had to ask. We had to email, we had to call, we had to ask for information. And when the initial 60 days was up, we called them and they 
were like oh 60 days is a theory. That would have been good to know because it's in the policy. At every single step the most frustrating thing was that there was no transparency and no effort to keep us informed. It was as if they were trying to keep us as uninformed as possible." - Clemencia

"My expectations naively were that it would take maybe a few months but that it wouldn't take a whole year. And it took an entire year. And that was with lots of pressure, lots of eyes on them [Title IX]." - Maybelline

As another example, Elpis reported to Title IX when she was a sophomore and waited until the semester she graduated for a resolution, without any accommodations that made her feel safe from seeing her abuser on campus. For Athena, she was never given timelines so had no idea when the investigation would be resolved. She hoped the investigation would be resolved by her birthday (months after the report filed), then she hoped it would be resolved by the year anniversary of the assault, and it was not. Several survivors had investigations that lasted a year or more. Rachel explained that this felt strategic: "It feels like they [Title IX] kind of want you to go away like they're trying to wait you out is what it felt like most of all." Title IX offices failed to take prompt or timely action in response to the reports filed, but expected participants to review documents and respond with little to advanced notice and a quick turnaround time. Yet, Title IX offices repeatedly surpassed timelines without any known consequence.

\section{Lack of proper support/resources}

Many participants reported to the Title IX office expecting support and resources to help alleviate effects of the harm they experienced. However, all but one of our participants were met with a lack of proper support resources to meet their needs $(\mathrm{n}=$ 20). To start, survivors like Keres and Brigid were not made aware of the possible accommodations and resources that Title IX could provide and were not informed of their rights as a student survivor. Six participants were given an overview of what to expect but the practice did not follow the process explained to them, and they did not receive answers when they asked for clarification. For example, Eos was never explained the process: "It [Title IX investigation] was an open process with very conflicting things being told to us at every level of what the process would look like." Irene was never informed of any counseling or other services at all which she felt was "very concerning". Rachel, Alethea, and Anaisa were not made aware that they could bring a support person or advocate to the Title IX meetings. Rachel did not find out until they found out her accused abuser had hired an attorney. Others like Tawny, 
Anaisa, and Harmonia would make requests for accommodations and resources that were frequently ignored or not met, most commonly safety concerns or accommodations to avoid the person who harmed them on campus. As Tawny stated: "We were begging for safety precautions and different things from Title IX and they refused to do any of it."

We found that several participants were provided with referrals for campus and/or community-based resources but were unable to access them. Bia was referred to a campus advocacy program and came to find that the university had dissolved the program three months earlier to which she stated "that was just another example of like okay [university] just isn't here to care." Elpis was referred to campus counseling, but when she went to make an appointment it was a month long wait list so she ended up finding (and paying for) a private therapist. Maybelline faced a similar situation, but could not afford counseling so went without support. When Brigid ultimately dropped out of her graduate program as a result of this experience, she lost access to her healthcare which was detrimental given her chronic health issues. Clemenica commented that she was "devastated" when she sought advice from campus legal services, but found they are "barred from helping" students in a Title IX investigation. Aletha was given a list of professors on campus who could advocate for her during the Title IX hearing, but because the hearing took place over Zoom during the covid-19 pandemic, she was unable to actually receive this support.

\section{Lack of protection}

On several occasions, participants commented about the HEI's failure to address their physical safety concerns regarding the person who harmed them $(n=15)$. Even though participants made their safety concerns known to the Title IX office, they were often not addressed leaving survivors to navigate campus safety on their own.

“They [Title IX] just never really put any interim measures in place. I had to get a restraining order against the guy who sexually assaulted me in court to have any real protection." - Rachel

"[Title IX] did not take us seriously when we brought forward safety concerns. I just think like downplaying those sorts of things allows them [HEI] to continue to like prop up that the university is doing everything in their power, and like these scary things that you all are afraid of aren't going to happen. Because if they were to admit to us that our safety was at risk or that they needed to intervene in some way, then the institution appears weak, right? - Tawny 
Ivy talked about the lack of protection she received against a professor who harmed her:

"We were getting more and more nervous about running into him. I am on campus until 9pm. What if I run into him and he's pissed? Because they [Title IX investigators] do this every day they forget how scary it can be." - Ivy

When physical safety concerns were minimized or ignored by the Title IX office, it altered their institutional experience. In several situations $(n=7)$, this led them to modify their academic schedules like switching to fully online courses, moving away from campus, or withdrawing from classes. Bia commented: "They [Title IX] provided no protective measures to make sure I could still continue my education." Ultimately, she ended up dropping all her classes but one that was offered online, so she could remain eligible for accessing campus counseling services. When the student who harmed Circe repeatedly violated the no-contact order, she asked the Title IX office to step in, to which the Title IX investigator laughed and said "it'll be resolved soon." Ultimately, Circe ended up dropping out of school: "How can you be on campus when your rapist is walking around?" With Keres the Title IX office removed a student from her class and imposed a no-contact order, despite Keres' expressed concerns. She described her feelings about the experience:

"Dealing with Title IX was worse than what actually happened and prompted me to contact them in the first place...I felt like the university didn't take adequate steps to try and ensure my safety" - Keres

For graduate students/workers, the issue of safety was complicated in a unique way. Keres (quoted above) again questioned the HEIs concern for survivors when they transferred this student to another woman graduate worker's class without notifying her that this student was potentially dangerous. Joanna, Tawny, and Ivy experienced this when their questions about safety went unanswered and the Title IX office released their names to the professors they filed against without warning or information on how they would be protected. They also shared concerns about the professors who harmed them having access to their personal information (e.g., home address), to which these complaints were ignored.

"I expected them [HEI] to be concerned with my position as a student that was reporting in relation to faculty. I expected for them to be practiced and knowledgeable about how to make people feel safe after reporting, how are you going to make students feel safe through this process, and even just being able to 
answer questions about those risks...It was like there was no concern there. No energy put forth, not many answers. And kind of just left in the dark." - Joanna

Participants who relied on the institution for employment but were harmed by their supervisor, were forced to choose between their employment and interacting with the person who harmed them.

\section{Lack of agency}

Participants frequently commented on the treatment they received or aspects of the investigation process that took away their power or agency $(n=15)$. In particular, we observed that institutional policies harmed or disadvantaged survivors' cases, or prevented them from withdrawing from the investigation. As Joanna commented, she "felt like a pretty consistent lack of control over the process" after she made her initial report and was then left with little information and concerns of her safety left unaddressed. Elpis and Ivy stated that they felt they had control over the initial decision to file a report, but then was left without any agency in the actual investigation. Ivy stated: "once the statement was out of my hands, I felt like I had no control." And Eplis: "I did feel like I could make that decision [filing a formal report] or just dropping the whole thing. But for the rest of the process I didn't feel like I had any sort of agency...I didn't feel like I could ever back out or anything."

Participants like Rachel experienced a lack of agency when they were unable to access their own investigation documents, similarly found by Smith \& Freyd (2014). When Rachel requested these documents through FOIA, they were redacted to the point where it was "impossible" to decipher. Not knowing what to expect, not being able access their investigative documents or updates about the investigation, and unexpected triggering contacts over the span of a lengthy investigation was a problem:

"Having the entire process be sort of very much behind closed doors even though the six of us and myself were willing to comply and be involved in the process as difficult as it was, but still having so much of what was going on be behind closed doors. We didn't know clear timelines. We didn't know what to expect when." Tawny

"I'm very uncertain about everything, all the time. And especially because I'm close to a hearing, I don't even know what's happening... This whole process, it's crazy that I'm close to a hearing and I still can't even tell you like what I'm doing... What's harmful too is that they withhold information from me. I'm an adult and I can decide what is in my best interests." - Athena 
"Absolutely not [any agency]. It was extremely, like a point where it all of a sudden became pushed and rushed like very forceful. Give us your witness. Give us this today. Like, it was a federal holiday and they were like submit this today by midnight otherwise you have no opportunity [to have this information included]." Nicole

We observed that multiple participants felt silenced by mandatory reporting policies because they could not speak openly about the harm they experienced without making a formal report to Title IX. In some cases, survivors reported to Title IX simply so they could speak openly about the harm they experienced and receive department accommodations such as explaining why they chose to remove an abusive professor from their dissertation committee. For example, Anaisa felt unsafe in her department and did not want to report to Title IX but stated "your only option to get somebody off campus is the Title IX process." As such, she felt that she had little agency from the beginning given the lack of viable options to receive accommodations that would help her to feel comfortable in her learning/working environment. In Andarta's situation, her experience was reported by a professor operating under mandatory reporting obligation without her knowledge. She was not informed that she was the victim in an investigation until seven months later when she was contacted for an interview. Andarta's betrayal stemmed from the fact that she intentionally did not share any information that would trigger a mandated report because she did not want to participate in an investigation. This clear lack of agency in reporting decisions is one example of the potential harms of compelled disclosure and mandated reporting (see Holland et al., 2018).

\section{Emotional labor}

When the Title IX office failed to act or respond adequately to complaints, the investigational burden frequently fell on the survivor. Survivors report to the Title IX office with the expectation of an investigation and accommodations, and when this does not happen it is the survivor that suffers. Consequently, survivors were often left with a significant amount of work to move the investigation forward, which we refer to using Hoschild's (1979) term emotional labor $(\mathrm{n}=13)$.

"It [Title IX] felt like jumping through hoop after hoop after hoop after hoop when the university should have just helped you...So I wasted my time and resources doing that. It never felt like anyone wanted to help me." - Circe 
"I can almost guarantee that I spent more time than they [Title IX] did on this case." - Ivy

"What we realized is they [Title IX] weren't gonna do any investigation or work... Going through Title IX really because like a second job. We became the investigators." - Eos

"It was my idea to put him [student perpetrator] in the online version of the class, and I was the one who looked up what his alternative options are. I felt like I was doing some of the work for them." - Keres

By doing their own investigative work when Title IX did not, Eos found that there was another woman who had experienced harm by this professor. In the final quote above, Keres explains that when Title IX stated they were unable to provide any accommodations that would allow her to continue teaching her course without the presence of the student who was stalking her, she ended up finding her own accommodation. This time and energy adds up especially when survivors also have the obligations of work, school, family, and the trauma of having experienced sexual violence.

\section{HEI self-protection from liability}

After participants described their experience with the Title IX office, we asked them why they think the HEI responded to them in this way. In response, we overwhelmingly found that participants came to find the (in)action by the HEI as an act of selfprotection from liability or reputation damages $(\mathrm{n}=14)$.

“Title IX isn't for you [survivors]. It's for the university" - Clemencia

"It's not in the university's best interest to say that harm has been done on their campus because then who is gonna want to go to a campus where people are raped, even though that is every campus. That is the reality already.... It's so much about maintaining the image of the university branding, protecting themselves from liability because ultimately the institution has to live on. If they're liable for things then the institution could cease to exist. So it's all about protecting the capital of the university." - Anaisa

"They [HEI] were more concerned with whatever reputation they wanted to uphold." - Andarta 
“[HEI] does not prioritize student safety and they don't address sexual and/or gender based violence. They are an institution that prioritizes money and their profits and their image. And that's the point: I think that they see survivors as a liability. It doesn't even feel like we're seen as human sometimes...[HEI] as an institution operates to silence survivors" - Bia

"They [Title IX] try and do the bare minimum to just protect themselves and their donor streams, and protect their good name, their reputation...The institution itself matters more than students who are actually what your values and mission are supposedly designed around. I feel that was an unspoken piece throughout, was protect the school, protect the department." - Harmonia

"I wish they [HEI] cared more about their community members and their safety as opposed to being nervous of him [perpetrator] suing them or reporting to the police, or having higher statistics around sexual assault... They only cared when they were in the spotlight." - Circe

These quotes demonstrate that with the advent of Title IX mandates, we may have moved beyond institutions overly responding to abuse complaints by "sweeping them under the rug" but it is still occurring in different forms. Rather than overtly refusing or discouraging survivors from filing reports, HEIs engage in other protective mechanisms like filing a report but not moving forward, or dragging the process out until the survivor drops out or the abuser graduates, which feel as if they are intentionally exhausting survivors (or as Maybelline commented: "peeling off” a group of survivors one by one until they mark the complaints as "addressed").

The inaction by the HEI on the behalf of graduate students/workers who experienced harm left many participants to feel like the HEI was serving to protect themselves from liability instead of student employees who had been harmed in their workplace and learning environment. For participants who were harmed by a faculty member, they noted that this institutional protection was extended to professors, but not to graduate students/workers, as Anaisa pointed out, the Title IX response is often a question of "who's more valuable to the university?" which speaks to the academic hierarchies that allowed the abuse to occur in the first place.

\section{Retaliation}

In some survivors $(\mathrm{n}=4)$, institutional betrayal was not only inaction or adequate response by the HEI, but extended to experiences of retaliation or punishment for filing a report with the Title IX office. 
"We're doing the right thing, even if it's in a system that punished you for doing the right thing." - Clemencia

"I was always concerned that he [professor who harmed her] could do something." - Anaisa

"I expected the Title IX office to intervene and stop this professor in the abuses that were happening. But the reality was that it made her more mad and she ended up retaliating because of it." - Irene

When Irene was experiencing retaliation for a professor she reported to Title IX for sexist, discriminatory treatment she was told by another professor to transfer schools. This speaks to the culture we refer to above, where Title IX encourages students to report, but then fail to protect them from retaliation.

\section{Responding to cases differently}

Participants $(n=6)$ felt that they were treated differently based on their personal characteristics and/or the circumstances of the assault. For example, Anaisa felt like her sexual assault complaint was not taken seriously because she was intoxicated at the time of the assault, which suggests a level of rape myth acceptance that impacts how cases are treated and is common in institutional responses to sexual violence (Hattery \& Smith, 2019; Venema et al., 2019).

Five participants alluded to sex/gender discrimination. For example, Elpis and Andarta felt dismissed and infantilized as a young woman reporting, and in Andarta's situation against a well-respected male professor. Brigid mentioned being treated as a "hysterical woman", but also feeling like her disability status was used against her and her queer identity was not recognized despite - in her opinion - it being central to the harassment she was experiencing. One participant described how confusing the Title IX process is to a student who comes from another country. Others experienced different treatment and access to support than the accused because of their race/ethnicity, as described by Rachel:

"I think because I'm a racial minority and because I was so new to the institution at that point, I think the school kind of viewed me as not a threat to them. They viewed him [the perpetrator] as more of a threat. He was a white male and he had money and a lawyer and was just threatening people with lawsuits...They were looking at it more from an institutional risk perspective rather than a justice, and I would say, morality perspective." - Rachel 
In these situations, participants felt betrayed by the HEI because Title IX failed to protect them and treated them differently in the process. As Rachel went on to explain, the secrecy and lack of transparency of Title IX processes allows for survivors to be treated differently, even those at the same institution with the same experiences.

For the graduate student/workers in our sample, several $(n=6)$ reported experienced confusing and differential treatment due to their student status. For example, Andarta felt she was taken less seriously because she was a new graduate student who had filed a report against a "well-respected male department chair." Keres explained the academic hierarchy and power structures contributed to this differential treatment:

"Being a graduate student complicates things because we have dual roles, where we are simultaneously a student of the university and someone who's a mandated reporter and in a position of power as instructors. So had I been a faculty member with an official professor title, maybe they [Title IX] would have taken my concerns more seriously" - Keres

These participants described that they felt the Title IX office was unable to fully understand the power dynamics present in a graduate student/worker reporting a faculty member who was harming them, which ultimately shaped their experience with the Title IX investigation.

\section{Discussion}

Institutional betrayal occurs when a member of an institution (e.g., student) is harmed by the institution through the institutions inaction, mishandling, or inappropriate response to the member's needs (e.g. equal access to educational opportunities; Freyd, 2013). We found that all participants in our study $(\mathrm{N}=21)$ felt betrayed by the university since they had lack of support, protection, and agency, and the onus was on them to check in on the process. The process itself seems to be overly bureaucratic and more tipped to protect the accused than the survivor, also evidenced by the amount of secondary victimization reported by survivors in a related paper from this sample (see Hayes et al., under review). Specifically, things like a lack of agency, feeling unprotected, emotional labor, and the timeliness of the investigation are all forms of institutional betrayal that overlap with the concept of secondary victimization (see Hayes et al., under review). We think this is in line with what scholars have suggested stating that the Title IX process is too similar to the criminal legal process (Javorka \& Campbell, 2021; Koss et al., 2014). The criminal legal system purports as 
supporting victims/survivors and that they provide an opportunity for justice, yet commonly result in further harm.

This further harm in this paper is Institutional Betrayal. This study builds on the limited research of institutional betrayal in HEIs, particularly Smith \& Freyd's (2013, 2014) quantitative conceptualizations such as retaliation, making it difficult to report, HEI self-protection, and creating an environment where abuse seems likely to occur. We specifically observed behaviors like denying survivors' access to their own records and investigation findings, and delaying investigation proceedings like interviewing perpetrators that have been found in Smith \& Freyd's (2014) research. Through grounded theory analysis, we identified several themes that illustrate the forms of institutional betrayal that one may experience in participating in a Title IX investigation. While our qualitative findings support these Smith and Freyd's (2013, 2014) findings, we also extend this conceptualization through identification themes like the HEI treating cases differently, lack of protection, emotional labor, and the length of the investigation. As such, we contend that the concept of institutional betrayal warrants further qualitative and quantitative research.

Our findings suggest that Title IX policies and their implementation are abusive via institutional gaslighting. Gaslighting is a form of manipulation that can occur when gender-based stereotypes, structural inequalities, and institutional vulnerabilities are mobilized against a person to "erode their realities" (Sweet, 2019, p.851). Title IX on campuses, including mandated reporting policies, are presented as a mechanism for providing students with support and accommodations but this is rarely the reality experienced. Yet, survivors in our study discussed being repeatedly told that everything was being done to ensure their protection and support, that their case was being taken seriously while simultaneously the survivors felt invalidated and dismissed. In other research, this has led survivors to question the reality of what they actually experienced ("crazy making"; Hayes et al., under review). Indeed, Title IX was enacted to ensure that students could have equal access to educational opportunities (U.S. Dept. of Education, 2020), but participants in our study were denied these opportunities during the Title IX investigation when the HEI failed to provide them with safe spaces during the investigation and ignored their concerns. In this study, almost half participants came to the conclusion that Title IX is actually a mechanism for the HEI's protection, masquerading as student protection. We were unable to explore this in the present paper, but gaslighting was found in examining Title IX among this same sample regarding secondary victimization (Hayes et al., under review) and our findings here also indicated that this could be occurring at the 
institutional level. It was a subtheme that did not hit saturation, but future research could ask more specific questions regarding the aspects of institutional betrayal that were found within this sample.

While both undergraduate and graduate students/workers experienced institutional betrayal, we found that there are different ways in which graduate students/workers experience betrayal given their different role within the HEI. Survivors who are graduate students/workers are in a unique position within the academic hierarchy, particularly regarding faculty who frequently control their access to educational, research, and job opportunities, funding, and completion of their thesis/dissertation. While graduate students/workers experienced institutional betrayal by the Title IX office, they also alluded to feeling betrayed (or protected, referred to as institutional courage; Freyd, 2014) by their department and/or faculty within their department. They discussed feeling like the Title IX process is built for undergraduate students and ill-equipped to respond to graduate students/workers. It was beyond the scope of this study to explicitly explore graduate student/worker experiences, but our findings - and the limited research to date - illustrate the importance of research that looks at graduate student/workers experiences, including Title IX but also their departments and other institutional members.

\section{Limitations}

There are several limitations to this study that we must acknowledge. First, our study included some racial/ethnic diversity, but does not reflect the composition of students who experience harm on campus. This may be due to low Title IX reporting overall, particularly among students of color (Lindquist et al., 2016). Regarding sexual orientation, we hoped to build on previous research (Smith et al., 2016; Smidt et al., 2019) examining Title IX experiences among LGBTQ students, but we lacked adequate representation in this sample. One participant mentioned feeling treated differently based on their identity as an international student, and we failed to have adequate representation of international students who may be at risk for experiencing institutional betrayal given their precarious student status. We encourage future researchers to over sample for survivors who are of marginalized status.

Second, our findings reveal that some survivors felt treated differently by the Title IX office based on some aspect of their identity or the circumstances of the case. These findings are based on the perceptions of the survivor, and while their feelings are valid, we did not systemically assess differential treatment and therefore cannot ascertain whether this treatment was indeed discriminatory. These preliminary findings add to 
extant research on differential treatment of LGBT students in Title IX processes (Smith et al., 2016) and the body of research showing that investigatory systems like the criminal legal process progress cases differently based on case and personal characteristics (Venema et al., 2019) which may apply to Title IX as well. We suggest that further research be conducted to explore discriminatory treatment in Title IX investigations.

Third, we failed to ask participants about the outcome they desired from the Title IX investigation. The questions we did ask led many participants to share the outcomes they wanted (and frequently did not receive) which largely surrounded ideas of validation, accountability, safety, and support. However, we cannot empirically state what survivors desire from this process, but this is essential information in making decisions about how HEIs can adequately respond to survivors. We urge further research to examine survivors' desired outcomes to determine what justice would be in these situations in order to build a system that meets survivors' needs and works to prevent harm in campus communities. Policymakers, particularly in a time where Title IX policies are being reviewed by the Biden Administration, need to be informed by survivors' experiences and needs.

\section{Implications}

Our findings considered with the extant Title IX research (e.g., Smith \& Freyd, 2013, 2014; Holland et al., 2018; Know Your IX, 2021; Smith et al., 2016; Smidt et al., 2019), we content that the Title IX process is not working for student survivors, and indeed is actively harmful to their well-being (Hayes et al., under review; Lorenz et al., under review). As Title IX proceedings evolve into a pseudo-legal process (Javorka \& Campbell, 2021; Koss et al., 2014) with fewer protections in place for survivors, the issues facing survivors appear to be largely structural and therefore not something that can be addressed only through investigator training and reform. Policies that remove agency from survivors like the denying access to investigation records, compelled (mandated) disclosure policies, and allow lengthy investigations without transparency must be eliminated to create space for procedures that are survivorcentered. We must critically examine how Title IX reinforces barriers to educational opportunities for survivors when it is intended to eliminate them (Lorenz et al., 2021). We must also consider the capitalistic influence in HEI's implementation of Title IX (and any future processes for responding to sexual violence) used as a mechanism for maintaining image and protecting from liability. For a truly survivor-centered process that aims to reduce and prevent harm, it cannot be adversarial and punitive, but 
should be restorative or transformative (Koss et al., 2014; Harper et al., 2017; Vail, 2019). Restorative/transformative processes place focus on accountability, with the goal of repairing harm and restoring people to wholeness while addressing other harmful structural factors such as racism, transphobia, ableism, etc. We encourage policymakers and HEI administrators to consider alternative reporting models (e.g., student/worker unions, responsible reporting policy; Kanik, 2017; North, 2019) that remove power from the HEI and give it back to survivors.

\section{References}

Ahrens, C.E., Campbell, R., Ternier-Thames, N.K., Wasco, S.M. \& Sefl, T. (2007). Deciding whom to tell: Expectations and outcomes of rape survivors' first disclosures. Psychology of Women Quarterly, 31(1), 38-49.

Cantor, D., Fisher, B., Chibnall, S., Townsend, R., Lee, H., Bruce, C., \& Thomas, G. (2015). Report on the AAU campus climate survey on sexual assault and misconduct. Association of American Universities, Rockville, MA.

Charmaz, K. (2006). Constructing grounded theory. London: Sage.

Corbin, J. \& Strauss, A. (1990). Grounded theory research: Procedures, canons, and evaluative criteria. Qualitative Sociology, 13(1), 3-21.

Corbin, J. \& Strauss, A. (2015) Basics of qualitative research: Techniques and procedures for developing Grounded Theory. ( $4^{\text {th }}$ ed.). Sage.

Corbin, J. \& Strauss, A. (2008) Basics of qualitative research: Techniques and procedures for developing Grounded Theory. ( $3^{\text {rd }}$ ed.). Sage.

Courtois, C. A., \& Ford, J. D. (2009). Treating complex traumatic stress disorders (adults): An evidence-based guide. NY: Guilford Press.

Creswell, J.W. \& Poth, C.N. (2018). Qualitative inquiry and research design: Choosing among five approaches ( $4^{\text {th }}$ ed.).

Cruz, J. (2021). The constraints of fear and neutrality in Title IX administrators' responses to sexual violence. The Journal of Higher Education, 92(3), 363-384. https://doi.org/10.1080/00221546.2020.1809268

Fisher, B.S., Daigle, L.E., Cullen, F.T., \& Turner, M.G. (2003). Reporting sexual victimization to the police and others: Results from a national-level study of college 
women. Criminal Justice and Behavior, 30(1), 6-38.

Freyd, J.J. (2014, July 14). Official campus statistics for sexual violence mislead. Aljazeera America. http://america.aljazeera.com/opinions/2014/7/college-campussexualassaultsafetydatawhitehousegender.html

Georgetown Voice Editorial Board (2021, April 16). Title IX fails the very group it exists to protect: Survivors of campus sexual violence. The Georgetown Voice. https://georgetownvoice.com/2021/04/16/title-ix-fails-survivors/

Glaser, B. \& Strauss, A. (1967). The discovery of grounded theory. Chicago: Aldine.

Grayer, A. \& Stracqualursi, V. (2020, May 6). DeVos finalizes regulations that give more rights to those accused of sexual assault on college campuses. CNN.

https://www.cnn.com/2020/05/06/politics/education-secretary-betsy-devos-title-ixregulations/index.html

Hattery, A.J. \& Smith, E. (2019). Gender, power, and violence. London: Rowman \& Littlefield.

Harper, S.B., Kirkner, A., Maskaly, J., \& Lorenz, K. (2017). Enhancing title IX due process standards in campus sexual assault investigations: Considering the role for procedural and distributive justice. Journal of School Violence, 16(3), 302-316.

Holland, K. J., Cortina, L. M., \& Freyd, J. J. (2018). Compelled disclosure of college sexual assault. American Psychologist, 73(3), 256-

268. https://doi.org/10.1037/amp0000186

Hoschild, A.R. (1979). Emotion work, feeling rules, and social structure. The American Journal of Sociology, 85(3), 551-575.

Javorka, M. \& Campbell, R. (2020). “This isn't just a police issue”: Tensions between criminal justice and university responses to sexual assault among college students. American Journal of Community Psychology, 67(1-2).

Kanik, H. (2017, October 29). UO creates new "Responsible Reporting” policy to support survivors of gender-based discrimination and harassment on campus. Daily Emerald. https://www.dailyemerald.com/news/uo-creates-new-responsible-reportingpolicy-to-support-survivors-of-gender-based-discrimination-andharassment/article_062c09d4-13b8-5a4d-9593-04772e29638f.html 
Know Your IX. (2021). The cost of reporting: Perpetrator retaliation, institutional betrayal, and student survivor pushout. Advocates for Youth.

Koss, M.P., Wilgus, J.K., \& Williamsen, K.M. (2014). Campus sexual misconduct: Restorative justice approaches to enhance compliance with Title IX guidance. Trauma, Violence, \& Abuse, 15(3), 242-257.

Lorenz, K., Shepp, V., \& O’Callaghan, E. (2021, October 11). Mandated reporting can trigger Title IX investigation without survivors' consent. Truthout. https://truthout.org/articles/mandatory-reporting-can-trigger-investigation-withoutsurvivors-consent/

Lorenz, K., Hayes, R., \& Jacobsen, C. (under review). "Keeping the wound open": Survivors' experiences with Title IX investigations.

Lindquist, C.H., Crosby, C.M., Barrick, K., Krebs, C.P., Settles-Reaves, B. (2016). Disclosure of sexual assault experiences among undergraduate women at historically black colleges and universities (HBCUs). Journal of American College Health, 64(6), 469-480.

North, A. (2019, October 10). What's next for \#MeToo? This college might have the answer. Vox. https://www.vox.com/identities/2019/10/10/20885824/me-too-movementsexual-assault-college-campus

Office of Civil Rights (2021, October 1). Pending cases currently under investigation. https://www2.ed.gov/about/offices/list/ocr/docs/investigations/openinvestigations/tix.html

Platt, M., Barton, J., \& Freyd, J. J. (2009). A Betrayal Trauma Perspective on Domestic Violence. In E.E. Stark, \& E. S. Buzawa (Eds.), Violence against women in families and relationships (pp. 185-207). Greenwood Press.

Rosenthal, M. N., Smidt, A.M. \& Freyd, J.J. (2016). Still second class: Sexual harassment of graduate students. Psychology of Women Quarterly, 40(3), 364-377. https://doi.org/10.1177/0361684316644838

Smidt A. M., Rosenthal, M. N., Smith, C. P., \& Freyd, J. J. (2019). Out and in harm's way: Sexual minority students' psychological and physical health after institutional betrayal and sexual assault. Journal of Child Sexual Abuse, 30(1), 41-55. 
Smith, C.P., Cunningham, S.A., \& Freyd, J.L. (2016). Sexual violence, institutional betrayal, and psychological outcomes for LGB college students. Traditional Issues in Psychological Studies, 2(4), 351-360.

Smith, C. P. \& Freyd, J. J. (2013). Dangerous safe havens: Institutional betrayal exacerbates sexual trauma. Journal of Traumatic Stress, 26(1), 119-124.

Smith, C. P. \& Freyd, J. J. (2014). Institutional betrayal. American Psychologist Journal, 69(6), 575-587.

Smith, C.P. \& Freyd, J.J. (2017). Insult, then injury: Interpersonal and institutional betrayal linked to health and dissociation. Journal of Aggression, Maltreatment, and Trauma, 26, 1117-1131.

Stader, D. L., \& Williams-Cunningham, J. L. (2017). Campus sexual assault, institutional betrayal, and Title IX. The Clearing House, 90(5-6), 198-202.

Strauss, A. \& Corbin, J. (1990). Basics of qualitative research: Grounded theory procedures and techniques. Newbury Park, CA: Sage.

U.S. Department of Education (2020, January 17). Title IX Regulations Addressing Sexual Harassment. https://www2.ed.gov/about/offices/list/ocr/docs/titleix-regsunofficial.pdf

Vail, K. (2019). The failings of Title IX for survivors of sexual violence: Utilizing restorative justice on college campuses. Washington Law Review, 94, 2085-2118.

Venema, R.M., Lorenz, K., \& Sweda, N. (2019). Unfounded, cleared, or cleared by exceptional means: Sexual assault case outcomes from 1999 to 2014. Journal of Interpersonal Violence.

Walsh, W.A., Banyard, V.L., Moynihan, M.M., Ward, S., \& Cohn, E.S. (2010). Disclosure and service use on a college campus after an unwanted sexual experience. Journal of Trauma \& Dissociation, 11(2), 37-41.

\section{Contributors}

Katherine Lorenz is an Assistant Professor of Criminology and Justice Studies at California State University-Northridge. She is a sexual violence researcher focusing on survivors' help-seeking and social reactions from informal and formal sources, including navigating institutional sources like Title IX, the police, and workplaces. 
Rebecca Hayes is a full professor at Central Michigan University. They have a coauthored book titled, \#Crime: Social Media, Crime and the Criminal Legal System, and has been published in journals such as, Violence Against Women, Crime \& Delinquency and Feminist Criminology. Their research interests are rape culture/sexual violence, inequalities in the criminal legal system, and medias impact on the criminal legal system.

Cathrine Jacobsen is a graduate student in the Sociology department at California State University-Northridge. Her research interests concern the role of social disparities as they inform the criminal justice system, where she is particularly interested in the intersections of structural race, gender, and age disparities as it pertains to the criminal justice system's responses to crime and its institutional processes.

\section{Footnotes}

1. We interviewed 22 participants total, but one participant's experience did not match the themes emerged from all the other participants and therefore is treated as an outlier. $\subseteq$ 